Herrn

Bundespräsident Pascal Couchepin

Vorsteher EDI

Inselgasse 1

3003 Bern

\title{
Für den Erhalt des Praxislabors
}

Sehr geehrter Herr Bundespräsident

Soeben bin ich im Labor meines Arztes zuverlässig, kompetent und prompt behandelt worden. Die rasche Verfügbarkeit der Resultate gibt mir Sicherheit und verhindert unnötige Zweitkontrollen. Durch die unkomplizierte und unmittelbare Art der Laboruntersuchungen entstehen für mich kein zusätzlicher Zeitaufwand und keine unnötige Verzögerung der Behandlung.

Ich schätze diese Leistung nicht nur sehr, ich bin darauf angewiesen. Ich fordere Sie deshalb auf, dafür zu sorgen, dass dies auch in Zukunft noch möglich sein wird.

Die von Ihnen geplante Revision der Analysenliste bedroht das Praxislabor meines Arztes ganz existentiell. Es ist für eine ärztliche Tätigkeit, die unseren Qualitäts- und Sicherheitsansprüchen gerecht wird, unverzichtbar.

Kurz: Ich bin nicht gewillt, auf die hohe medizinische Qualität der praktizierenden Ärzte zu verzichten, und wehre mich gegen jede Form des Abbaus - insbesondere gegen den Verzicht auf das Praxislabor. Deshalb bitte ich Sie, die Revision der Analysenliste in der heute vorgesehenen Form zu stoppen.

Mit freundlichen Grüssen

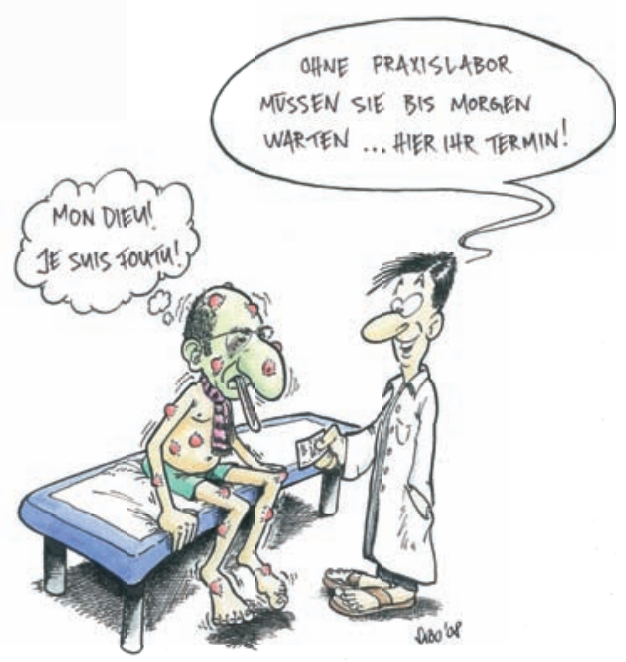

Bundesrat Couchepin will das Praxislabor abschaffen 